\title{
Study of Emotional Analysis About Pandemic Situation During Covid Era Editorial and Social Media
}

\author{
Jolly Masih ${ }^{1 *}$, Rajkumar Rajsekaran ${ }^{2}$, K Govinda ${ }^{3}$, Neha Saini ${ }^{4}$ and Mohit Sharma ${ }^{5}$ \\ ${ }^{1}$ Prestige Institute of Engineering Management and Research, Indore, India \\ ${ }^{2,3}$ VIT, Vellore, India \\ ${ }^{4}$ BITS, Mesra, India
}

${ }^{5}$ Dr. Rajendra Prasad Central Agricultural University, Samastipur, Bihar

*Corresponding author: Jolly Masih, Prestige Institute of Engineering Management and Research, Indore, India

\begin{tabular}{|c|c|}
\hline ARTICLE INFO & ABSTRACT \\
\hline & \multirow{3}{*}{$\begin{array}{l}\text { Present study is one of its first kind enlightens the importance of social media } \\
\text { surveillance for tracking the public sentiments to encapsulate in government advisory } \\
\text { and other policy amendments. Quantitative behavioral data from all round the globe } \\
\text { were collected and analyzed using Talk walker software from last week of April } 2020 \text {. } \\
\text { Mainly, social, and editorial media was used for study purpose. Findings revealed } \\
\text { interesting buzzing around COVID } 19 \text { as most popular hashtag on internet with millions } \\
\text { of conversations. Further, study also analyzed demographic assessment of social media } \\
\text { related to COVID } 19 \text { and mostly people were anxious to know about the current scorecard } \\
\text { of cases generated through pandemic. Additionally, government interventions from time } \\
\text { to time and vaccine for virus were central themes for social media sensations. Findings } \\
\text { of this study can help for suitable advisory and timely interventions to co-up the mental } \\
\text { retardation of people during this pandemic. }\end{array}$} \\
\hline Published: 㓞 November 13, 2020 & \\
\hline $\begin{array}{l}\text { itation: Jolly Masih, Rajkumar Rajseka- } \\
\text { an, K Govinda, Neha Saini, Mohit Sharma. } \\
\text { tudy of Emotional Analysis About Pan- } \\
\text { lemic Situation During Covid Era Editorial } \\
\text { nd Social Media. Biomed J Sci \& Tech Res } \\
\text { 1(5)-2020. BJSTR. MS.ID.005171. }\end{array}$ & \\
\hline
\end{tabular}

\section{Introduction}

COVID -19 flied to our world like a "Black Swan" in December 2019 and became the global pandemic [1]. The outbreak and rapid spread of the Disease has imposed (life) critical threats and challenges to individuals and societies (WHO 2020). In the absence of an effective vaccine, it is of utmost importance to reduce the stretch of COVID-19 to set aside timely treatment of infected individuals. In order to decelerate the effects of present endemic, health and political advisories around the world have evolved regulations aimed at limiting the number of physical contacts between people through social and physical isolation at home and it has been adopted by most of the affected countries, provoking millions of people confined to their home [2,3]. However, this measure carries risks for people's mental health as this time of crisis is generating stress throughout the population (WHO 2020), carrying the specter of an increased burden to mental health, both in terms of existing psychiatric disorder, and emerging psychological distress from the pandemic [4,5]. During the outbreak of present pandemic, investigation on public psychological states and associated factors revealed high rates of non-anxiety (94 per cent) and non-depression rates (83 per cent). Such severity in terms of anxiety (6.33 per cent) and depression (17.17 per cent) is on disquieting towards the psychological states of the people [6].

Existing literature identified that the mental health and psychosocial outcomes of the COVID-19 pandemic may be especially serious for at least four group i.e. healthcare workers engaged in frontline response to the pandemic and their family, second the individuals who will experience the emergence of new mental health distress as a function of being diagnosed with COVID-19, or losing family and loved ones to the illness, threats to one's health and to the ability to work and make a living or the psychological effects of prolonged social distancing, thirdly individuals with existing mental health conditions who are either diagnosed with COVID-19 or whose experience of social distancing exacerbates existing vulnerabilities and finally the people who are following 
the news through numerous media channels [7-12]. In context of outreaching the guidelines towards rural masses comprising health care, the role of social media becomes prominent. Various governments around the globe advocated and realized the use of e public media platforms like ask Nivi, Corona Map and Arogya Setu by Kenya, South Korea, and India, respectively. These e-platforms are basically AI (Artificial Intelligence) and specifically designed to track the customers' health status and more importantly acting as friend to them by updating on day to day health care practices. Various IT companies have come forward to assist general public on sensitizing towards pandemic by developing free interactive chat sessions [13].

These platforms provide FAQs as well as dynamic platform for live interaction with automated replies on query sessions related to health care services. Evidence can also draw from USA which has developed 'Natural Cycles' birth control app along with in-built tracker to address Covid-19 crisis. Connecting home quarantined along with health care worker is also provisioned under this app for catering prompt dealing for symptoms [14]. Various mobile based platforms along with Global Digital Health Network (GDHN) developed for creating best possible tech saviors for communicating disease advisory to general masses. 'Commcare', 'Safiri Smart' and 'Praekelt' are some of the leading mobile platforms, who under the association of GDHN started virtual special convention on the pandemic during 2nd week of March 2020. India, being the second most populous country worldwide, utilized tech platform in the form of 'Aarogya Setu' to sensitize its masses about risk, time to time advisory and best practices to keep them safe from the present endemic [13-15]. On account of disseminating authentic and necessary advisory on present pandemic, World Health Organization (WHO) and Ministry of Health and Welfare in respective country utilizing their official website and social media platforms [13]. Most popular and effective online platforms like Facebook, Twitter, YouTube, and Instagram have showed immense importance in dissemination advisory related to Covid-19.

Regardless of the quality and source, various information from the media platform is highly accessible and timely, so further analysis can be performed if the data can be collected and processed properly [14]. Al (Artificial Intelligence), one of most powerful and popular tools to handle big data have been utilized to have better understanding of the social network dynamics and to improve the Covid-19 situation [15]. To further explain the application of AL during the disease pandemic, the work has presented some reallife examples-1) use of social media example twitter data to track the public behavior, 2) examining the health seeking behavior of the Covid-19 outbreak [16-24]. Another recent study in China, where public emotion is evaluated by using text analysis program called Linguistic Inquiry and World Count (LIWC), whereas public attention and awareness and misinformation is evaluated by contracting a 'Weibo daily index', which means the number of posts with keywords related to the Covid-19 pandemic. Furthermore, the two 'Baidu' and 'Ali daily indices' are used to evaluate the intention and behavior to follow the recommended safeguard measures and / or rumors about futile treatments during the outbreaks of Covid-19. The result of the evolutions depicts that urgently classifying rumors and misinformation can greatly alleviate the impact of irrational behavior [25-27].

Repercussions of dreadful pandemic Covid 19 may lead for dismantling public health emotions and behavioral changes either heartening ones (adhering to government guidelines and taking personal care with sanitization, social distancing) or deterrent (unrequited anxiousness, phobia generated through news, societal unease). This necessitates the prominent role of government during era of epidemic to route and disseminate authentic and timely information upon recognizing public emotions and sentiments. Due to high free time with the public, social media is new lockdown friend and widely using as a platform to diffuse endemic related information for masses. As the evil resides in detail, scrutiny over this platform may be extended to assess foremost retaliation by general public to key guidelines and decision makers can speculate for any buzz and half-truths. Such practices may give real time advantage over routine survey for structural monitoring of real emotions and further discarding biasness [28]. As evident from past literature, very few studies have explored the prospect of surveillance through popular social media platforms like face book and twitter during the era of pandemics likes H1n1 and Ebola. It was only during 2009/2010 when the prominent role of social media was adopted for risk communication during outbreaks of dreadful diseases. Incorporation of such vital platforms and realizing the role of social sciences has advocated as one of key research precedence by many practitioner and officials at WHO [29,30].

This is one of its first kinds of research by using social media platform to assess the general public awareness, attention, risk sensitization towards pandemic, sentiments and other behavioral responses emerged during the era of Covid-19. Thus, this study paves a path to government and policy makers to understand the public emotion about Coivd-19 crisis using the real time data and to come up with suitable Covid-19 relief strategies and plans. Keeping the above in consideration at this present juncture it becomes severely important to enlist and conduct the emotional analysis of people creating through this epidemic so that suitable and timely interventions can be issued in terms of advisory to co-up the mental retardation of people.

\section{Methodology}

\section{Data Collection}

The data was collected from social media surveillance software called "Talkwalker", to evaluate public attention and behavioral sentiments, awareness, and emotions, "use of drones in Covid-19 outbreak" in real time. 


\section{Time Period}

Software provides data analysis of one week so chosen dates were $20^{\text {th }}$ April 2020-26 ${ }^{\text {th }}$ April 2020. The data was collected worldwide.

\section{Data Source}

Talk walker mediated platforms such as Twitter, online news, blogs, magazines, YouTube, press release, TV/radio and VKontakte.

\section{Data Type}

Quantitative behavioral data including Twitter tweets, online news, blogs, newspaper, forums, news agency, magazines, YouTube, press release, TV/radio and some other forums were used to collect and asses the data on public sentiment about "use of drones in Covid-19 outbreak" (Figure 1). Twitter was major source of information since most of the people put their views and sentiments on their Twitter social media account and its data is freely accessible. Online news and blogs also provided large quantities of data since drones are being used all over the world for surveillance, providing medical assistance, sanitization, identification of Covid-19 patients etc. News channels and bloggers are constantly covering all updates about this topic. Other sources mentioned in graph also provided minute information about the topic. Please note that these platforms were selected by default while using the "Talk walker" software in data collection and analysis.

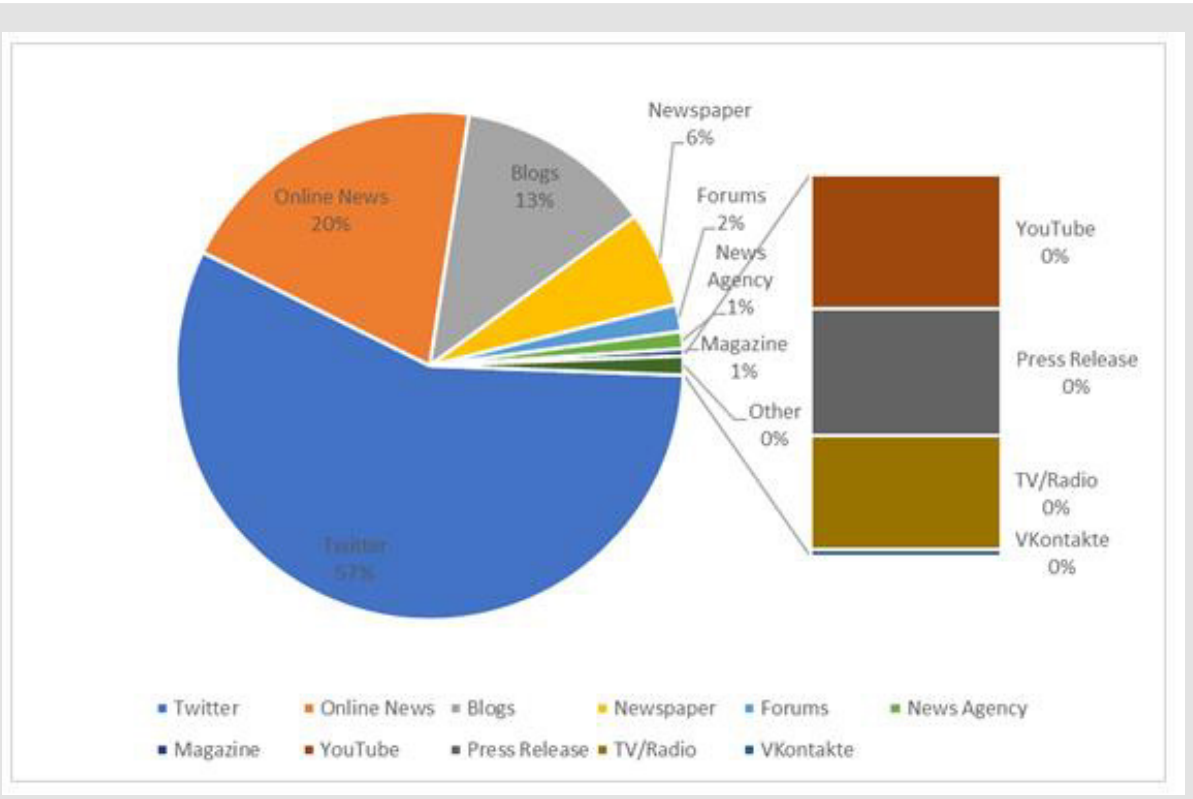

Figure 1: Sources of online mentions about the theme "use of drones in Covid-19".

Note: Source: www.talkwalker.com.

\section{Results}

\section{Worldwide Mentions About Covid-19 Pandemic Via Social Media and Editorial Media}

(Figure 2) above clearly depicts that the maximum number of mentions about Covid-19 pandemic were in the USA ( 8 million) due to high number of deaths $\left(1 / 4^{\text {th }}\right)$ and infectious $\left(1 / 3^{\text {rd }}\right)$ followed by Europe which reported around 5 million mentions where countries like Spain, Italy, France, Germany, United Kingdom and Turkey have badly suffered. South America and Indonesia reports around 2 million mentions which are further followed by India reporting one million mentions. The above figure shows that maximum number of mentions have been done in English language i.e., around 55.2\%, as English is still the most used language on social media. It is further followed by Spanish (18.9\%), Portuguese (6.1\%) and French (4.7 $\%$ ) as these countries are highly infected by the deadly virus and are actively writing on the social media about the Covid-19 pandemic.

\section{Who is talking about Covid-19 Pandemic on Editorial and Social Media?}

(Figure 3) reveals about the sentiment analysis of gender demographics via social and editorial media and it was found that only $29.7 \%$ of females had posted or mentioned about the Covid-19 pandemic. However, in contract to females, a lot of males (70.3\%) have actively written about the Covid-19 pandemic, its causes, and potential ways to fight it. Moreover, it was found out that the fatality rate was higher in males (2.8\%) than female (1.7 $\%$ ). Our study found that males were more curious and anxious about Covid-19 crisis and one potential reason could be that males are more likely to get infected by this virus as compared to females (as per study of Imperial College London, (Figure 4). Some studies also reported that in Italy, out of total deaths occurred due Covid-19, 71\% were men. In Spain, media reported that men are $50 \%$ more susceptible of catching this virus compared to women [12]. (Figure 3) also shows that most active on social media writing 
about Covid-19 pandemic (about 35.3\% mentioned were obtained from them) were middle age to old people (45-54 years) since this age group was most vulnerable to get infected by the Corona virus.

Rest of the mentions about Covid-19 came from age group 25-34
(32.4\%, mostly working-class people) and age group 18-24 years (29.4\%, mostly students) who were worried about their jobs and universities being closed down.

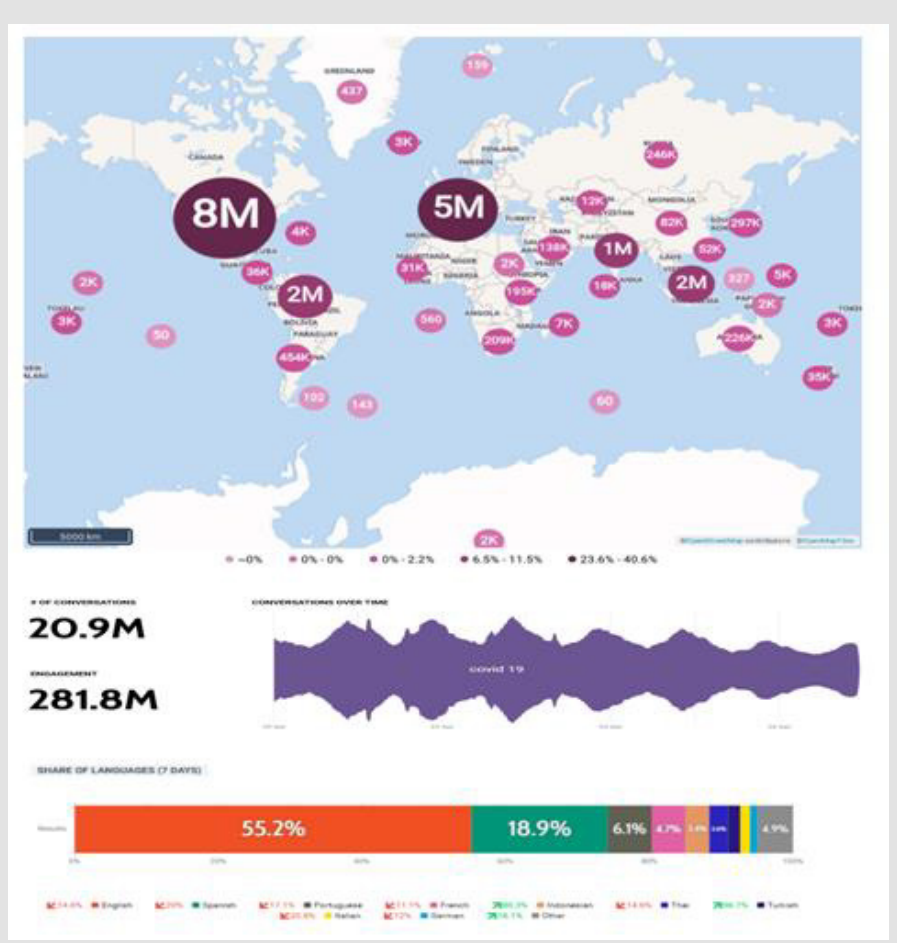

Figure 2: World-wide media mentions about Covid-19.

Note: Source: www.talkwalker.com.
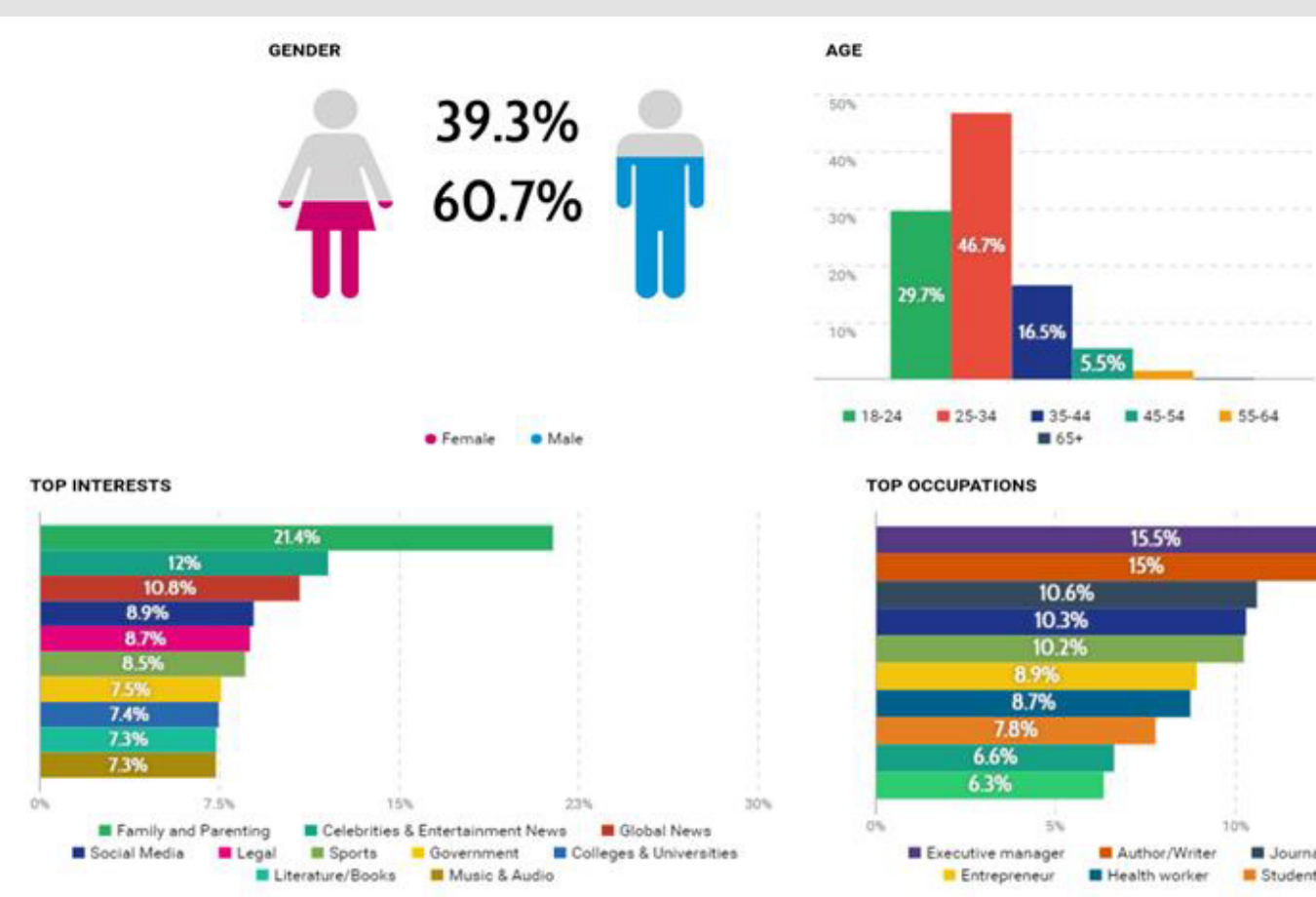

TOP OCCUPATIONS

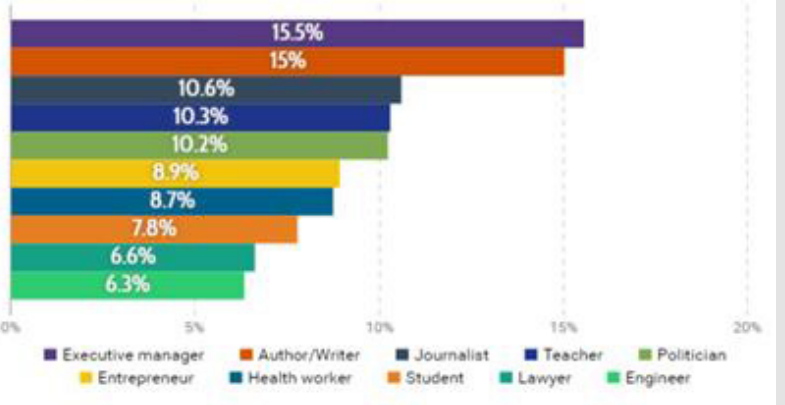

Figure 3: Demographic details about Covid-19 mentions.

Note: Source: www.talkwalker.com. 


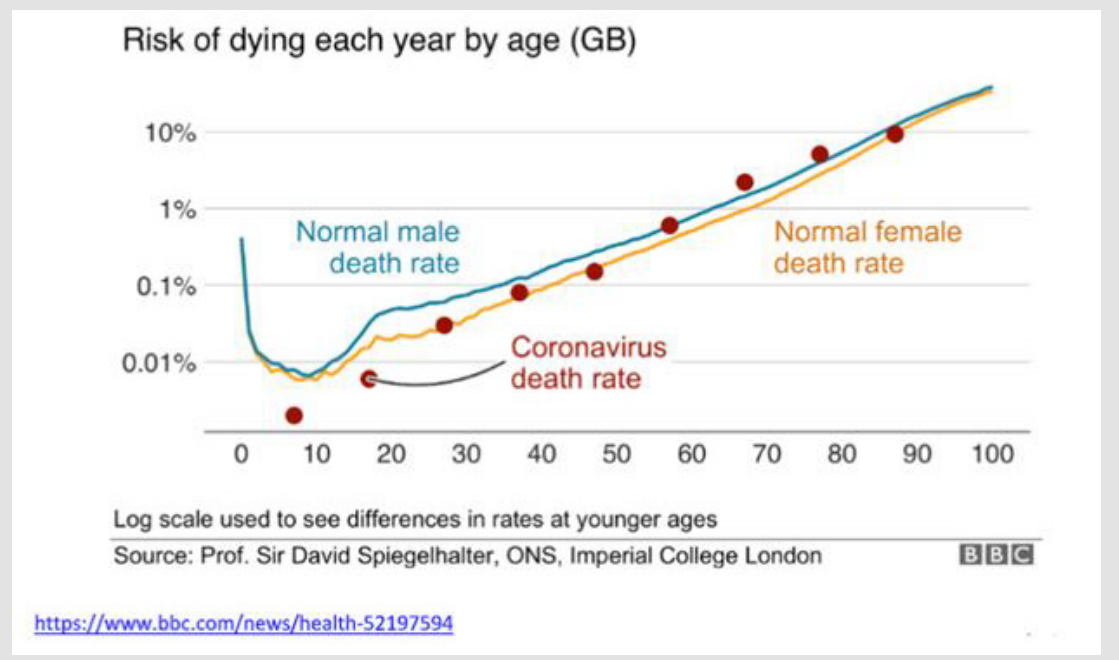

Figure 4: Males and more susceptible to Covid-19 infection compared to females.

The graph depicts that around $82 \%$ of the articles and social media posts were written in English language followed by Dutch (12 $\%$ ) and Hindi (5.5 \%) as English is still the most widely used global language. (Figure 2) also depicts the top interest of the people who have written about Corona virus. It was found that mostly people from literature and arts background (example, bloggers, novelist, journalist, authors, writers etc.,) wrote actively about this issue (33.3\%). About $16.7 \%$ mentions were from science and medicine field, writing about the symptoms, remedies, causes and sources of origin of Corona virus. The (Figure 2) also mentions the top occupation of the people who have contributed to writing about the Covid-19. It reveals about $52.2 \%$ online mentions are written by professional writers, bloggers, and authors; followed by $42.5 \%$ executive managers, which have suffered considerable losses due to the economy breakdown and loss of employment and businesses.

\section{What Things Are Talked About Covid-19}

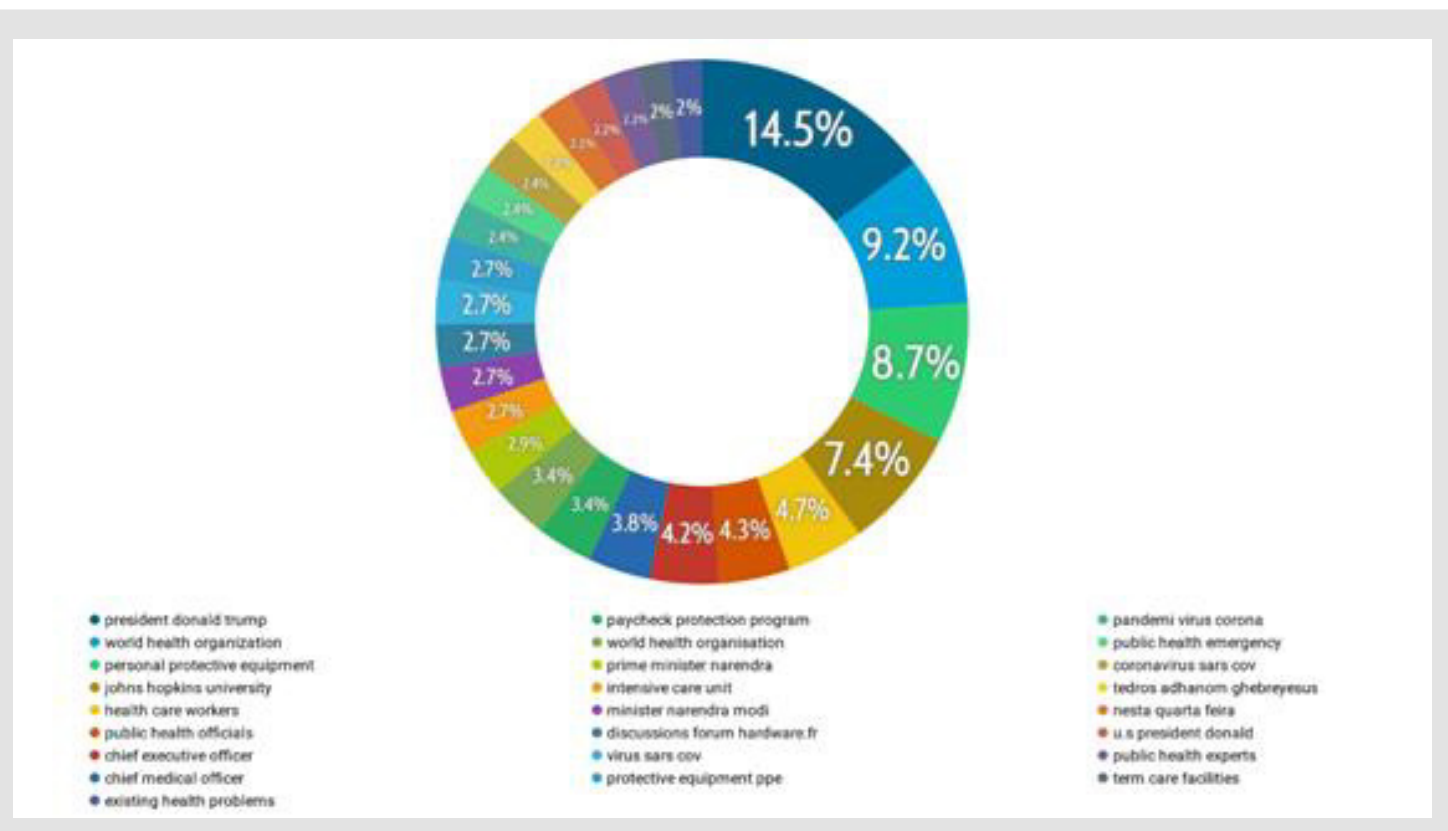

Figure 5: Top themes related to Covid-19 mentions.

Note: Source: www.talkwalker.com.

(Figure 5) shows that the top themes which are discussed majorly on the various platforms of editorial and social media are about President Donald trump (14.5 \%) and his statements about downplaying the Covid-19 crisis in USA leading to national job crisis and economic fallout. The second most popular mention was about World health Organization (9.2\%) due to increased fact-checking and a pop-up that directs users who search for corona virus directly to the WHO's website or a local health authority. Followed by 
Personal Protective equipment (8.7 \%) as it is the most important in preventing the transmission of the deadly virus are also trending in the social media pertaining to the topics of their market, demand, availability and also growing awareness regarding workers' health and safety. (Figure 6) shows the top hashtags which are trending most on social media are ---COVID-19 with $35.8 \%$ hashtags globally across social media and various news sites. Exceptional and record conversations are happening over the social media due to its widespread effects covering almost the complete global, so such responses are obvious over the social media platform. It is further followed by \#corona virus which has seen its highest level of search traffic - this incremental trend followed a number of popular and high quantum news covering and explicating present endemic.

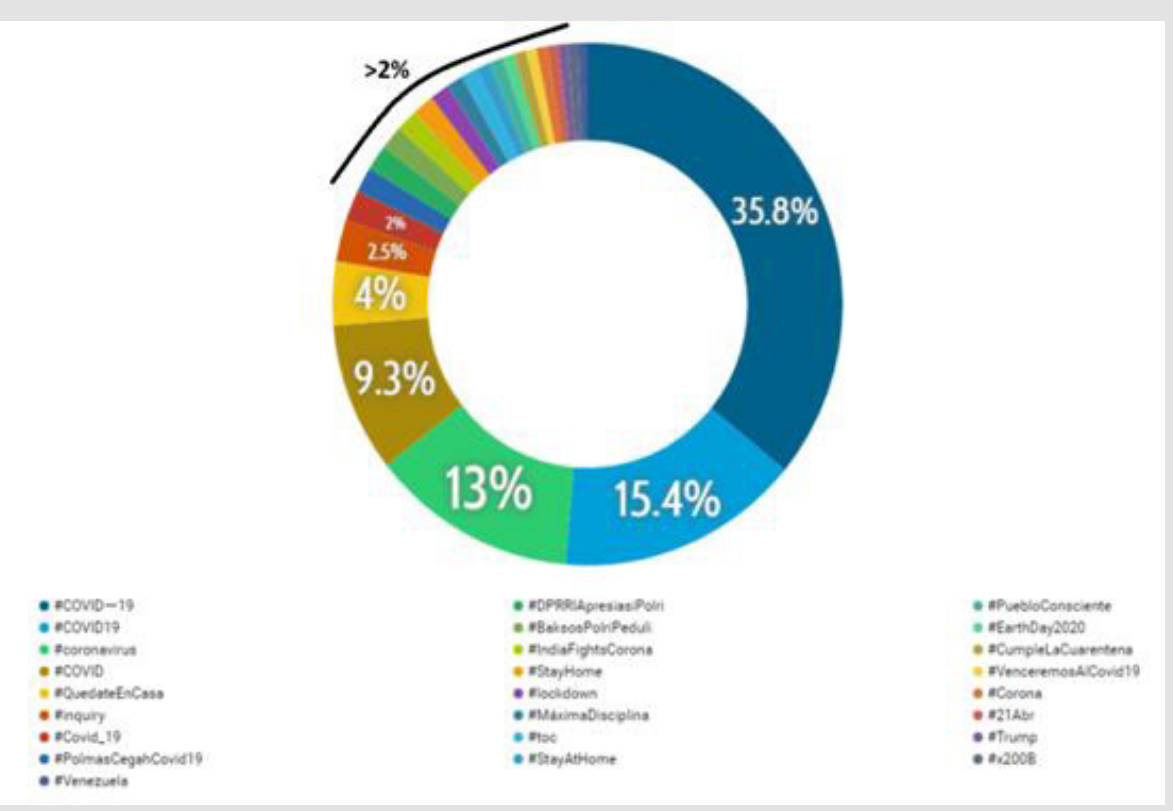

Figure 6: Top hashtags related to Covid-19 mentions.

Note: Source: www.talkwalker.com.

\section{World Majors Talks About Covid-19}

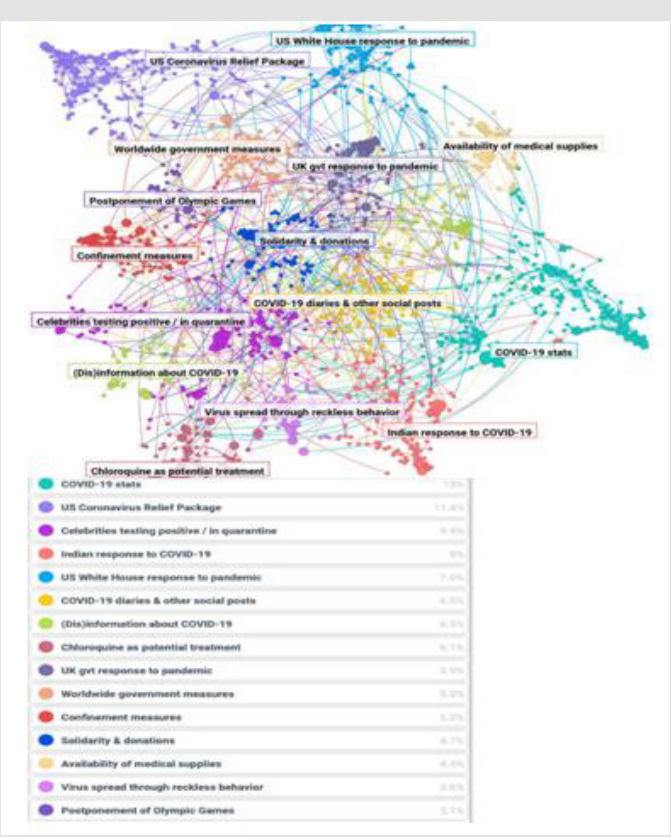

Figure 7a: Covid-19 social media cluster 1 identified on20 ${ }^{\text {th }}$ April 2020.

Note: Source: www.talkwalker.com. 
Web users around the globe have largely utilized the services of popular platforms such as Facebook, Twitter, and LinkedIn. Analysis of these platforms helps for "summarize the interests and opinions of users (nodes), discovering patterns from the interactions (links) between users, and mining the events that take place in online platforms." Further many valuable applications can be enriched and explored with utilizing information gathered through these platforms (Figures 7a \& 7b). Neural Network map depicts the most searched topics on the social media "Covid-19 stats" as people all over the world usually check the status of the people infected with Covid-19 globally or in their country. "US Corona Virus relief packages, the US House of Representatives devastatingly approved a $\$ 484$ billion corona virus relief bill towards funding small businesses and hospitals and pushing the total spending response to the crisis to an unprecedented near \$3 trillion" which is next most searched topic. "Celebrities testing positive "is another trending topic with so many top celebrities and sportspeople tackle to restrain the stretch of virus leading to cancellation of many high-profile events. Other important topic of conservation amongst global public were how India responds to Covid-19 through a massive lockdown, Chloroquine-the medicine of malaria as potential treatment of corona, deadly virus spreading through reckless behavior of people, postponement of Olympic games, UK government response to pandemic, availability of medical supplies and worldwide confinement measures to reduce virus spread.

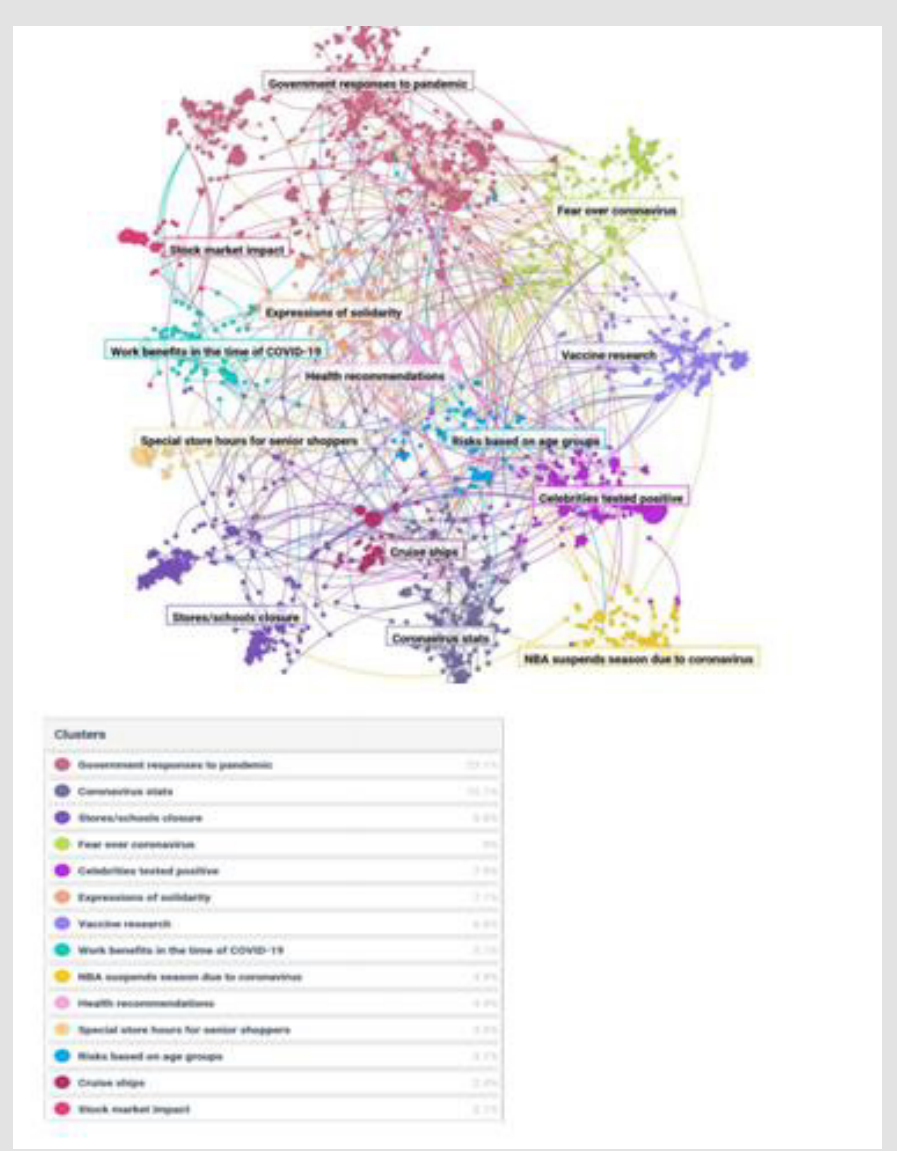

Figure 7b: Covid-19 social media cluster identified on 26 th $A$ pril 2020.

Note: Source: www.talkwalker.com.

In second social media cluster of the analysis, it was found that most of the people across the globe (23.1\% mentions) were talking about government measures to fight Covid-19. People were regularly checking Covid-19 statistics (10.1\% mentions) about number of cases and number of deaths, thus this second most important node found in the social media cluster. Due to locked down across the world (9.6\% mentions), the schools and universities were closed, and fear of virus rose exponentially widewide ( $9 \%$ mentions). Other important issues which were discussed in last week of April of social media were vaccine search for corona virus, old age people being more susceptible to the infection, health recommendations to improve the immune system and crash of stock market in Covid-19 pandemic.

\section{Conclusion}

This is one of novel research in realizing the emotional attitude of people in present crisis of COVID-19. Collection of data was from social media surveillance software 'Talk Walker'. It was assessed 
to study public attention, awareness, behavioral and emotional sentiments etc. Findings revealed that worldwide media mentions more about USA. This is probably due to the reason of maximum death and infections, USA had during this pandemic. Around half of mentions were in English language due to its popularity and most spoken language over the internet. Sentiment analysis of gender demographics stated the dominance of males over posting and speaking over present pandemic. This draws out the point of anxiousness and curiosity faced by men as compared to their counter parts. Studies of countries like, Italy and Spain revealed the major death due to this pandemic was of males. As per WTO there is no certain age group which is depriving from this infectious disease but people in age group of 45-54 are most vulnerable. Results showed that around 35\% of the respondents of this age group were most active and responding most on this pandemic. Mostly the people from literature and arts background were proactive to pen down effects of this pandemic.

Even though high number of executives (42.5\%) showed their responses over the pandemic as this situation was more drastic for them on economic point of view. Other most popular themes discussed over social media were USA President and WHO followed by personal protective equipment and their availability. Most common hashtag was \#coronavirus across social and editorial media globally. Mostly, people were anxious on the daily number of corona virus patients and responses of the local authorities to them. As various globally recognized celebrities were tested positive in this pandemic, so it was also trending over the social media. During this pandemic, response rate of individual country was different, some had taken precautionary measures and other delayed the process. It was the trade off in economy over the people or people over the economy. So, individual country response and measures to fight against this pandemic was also talked about most of the people. Vaccine search and stock market crashing was also one of the trendy topics among general public around the globe. Present study has many implications in governing the response of the government and policy makers over unprecedented pandemic. Social media surveillance for risk assessment can be useful for practitioners to take up timely and needed interventions to tackle mental retardation of the people.

\section{References}

1. Aman Sharma, ET Bureau (2020) Mind your mind: Govt's advice on dealing with lockdown blues in fight against Covid-19.

2. Brooks SK, Webster RK, Smith LE, Woodland L, Wessely S, et al. (2020) The psychological impact of quarantine and how to reduce it: Rapid review of the evidence. The Lancet 395(10227): 912-920.

3. Fiorillo A, Gorwood P (2020) The consequences of the COVID-19 pandemic on mental health and implications for clinical practice. European Psychiatry 63(1): e32.

4. Fiorillo A, Gorwood P (2020) The consequences of the COVID-19 pandemic on mental health and implications for clinical practice. European Psychiatry 63(1): e32.
5. http://www.euro.who.int/en/healthtopics/healthemergencies/ coronaviruscovid19/news/news $/ 2020 / 3 /$ mental-health-andpsychological-resilience-during-the-covid-19-pandemic extracted on 10/04/2020.

6. Adriana Panayi (2020) COVID-19 Is Likely to Lead to an Increase in Suicides.

7. CPA Webmaster (2020) Psychology Works" Fact Sheet: Psychological Impacts of the Coronavirus (COVID-19).

8. Rohit KVN, DH Web Desk (2020) Indian govt brings COVID-19 tracker app Aarogya Setu.

9. https://www.indiatoday.in/india/story/coronavirus-pm-modi-9pm9 minute-call-lights-up-nation-as-covid-19-cases-continue-to-soardevelopments-1663684-2020-04-06 extracted on 10/04/2020.

10. https://www.newindianexpress.com/states/telangana/2020/mar/24/ while-people-clapped-for-those-in-frontlinefightingvirustelanganaland lordsleavedoctorshomele2120839.htmlextractedon10/04/2020

11.h t tp s: / / w w w. u a.e d u / n e w s / $2020 / 03 /$ u a - t o studyhowemotionsimpactbehaviortocovid19pandemic/.

12.(2020) Mental health and psychosocial considerations during the COVID-19 outbreak.

13. Inchausti F, Mac Beth A, Hasson Ohayon I, Dimaggio G (2020) Psychological intervention and COVID-19: What we know so far and what we can do. J Contemp Psychother $27:$ 1-8.

14. Li Q Guan X, Wu P, Wang X, Zhou L, et al. (2020) Early Transmission Dynamics in Wuhan, China, of Novel Coronavirus-Infected Pneumonia. N Engl J Med 382: 1199-1207.

15. Pancani L, Marinucci M, Aureli N, Riva P (2020) Forced social isolation and mental health: A study on 1006 Italians under COVID-19 quarantine. PsyArXiv.

16. Petropoulos F, Makridakis S (2020) Forecasting the novel coronavirus COVID-19. PloS one 15(3): e0231236.

17. Teoh K, Kinman G (2020) Looking after doctors' mental wellbeing during the covid-19 pandemic. BMJ Opinion.

18. Wang C, Pan R, Wan X, Tan Y, Xu L, et al. (2020) Immediate psychological responses and associated factors during the initial stage of the 2019 coronavirus disease (COVID-19) epidemic among the general population in china. International Journal of Environmental Research and Public Health 17(5): 1729.

19. Wang Y, Di Y, Ye J, Wei W (2020) Study on the public psychological states and its related factors during the outbreak of coronavirus disease 2019 (COVID-19) in some regions of China. Psychology, Health \& Medicine p. $1-10$.

20. (2020) WHO. Rolling updates on coronavirus disease (COVID-19).

21. Williams R, Murray E, Neal A, Kemp MV (2020) Top ten messages for supporting healthcare staff during the covid-19 pandemic.

22. Wind TR, Rijkeboer M, Andersson G, Riper H (2020) The CoVID-19 pandemic: The 'black swan' for mental health care and a turning point for e-health. Internet Interventions 20: 100317.

23. (2020a) World Health Organization. Mental health and psychosocial considerations during the COVID-19 outbreak.

24. (2020) www.cdc.gov.in.

25. https://coronamap.site.

26. (2020) https://play.google.com/store/apps/details?id=nic.goi. aarogyasetu.

27. https://medium.com/zenysis.

28. K Ganasegeran, SA Abdulrahman (2020) Artificial Intelligence Applications in Tracking Health Behaviors During Disease Epidemics. Cham: Springer International Publishing pp. 141-155. 
29. Z Hou, F Du, H Jiang, X Zhou, L Lin (2020) Assessment of public attention, risk perception, emotional and behavioural responses to the Covid-19 outbreak: Social media surveillance in China. Risk Perception, Emotional and Behavioural Responses to the Covid-19 Outbreak: Social Media Surveillance in China.

\section{ISSN: 2574-1241}

DOI: $10.26717 /$ BJSTR.2020.31.005171

Jolly Masih. Biomed J Sci \& Tech Res

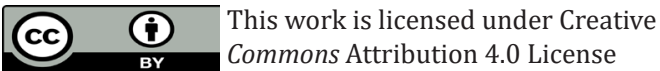

Submission Link: https://biomedres.us/submit-manuscript.php
30. Hou Z, Du F, Jiang H, Zhou X, Lin L (2020) Assessment of public attention, risk perception, emotional and behavioural responses to the Covid-19 outbreak: Social media surveillance in China. Risk Perception, Emotional and Behavioural Responses to the Covid-19 Outbreak: Social Media Surveillance in China.

$\begin{array}{ll}\text { BIOMEDICAL } & \text { Assets of Publishing with us } \\ \text { RESEARCHES } & \text { - Global archiving of articles } \\ \text { - Immediate, unrestricted online access } & \text { - Rigorous Peer Review Process } \\ & \text { - Authors Retain Copyrights } \\ \end{array}$

